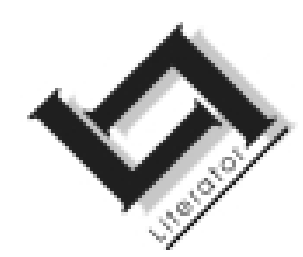

\title{
Betekeniskonstruksie as kreatiewe proses: 'n tekslinguistiese benadering
}

\author{
la Esterhuizen \\ Skool vir Tale \\ Vaaldriehoekkampus \\ Potchefstroomse Universiteit vir $\mathrm{CHO}$ \\ VANDERBIJLPARK \\ E-pos: afnme@puknet.puk.ac.za
}

\section{Abstract}

The creative process of meaning construction: A text-linguistic approach

The main aim of this article is to explore the usefulness of text linguistics in determining how and why a literary text creates meaning. In order to achieve this aim, the unique way in which a writer or reader creates a text by means of lexico-grammatical and conceptual elements is discussed.

The meaningfulness of the linguistic analysis of literary texts is then illustrated by an analysis of T.T. Cloete's poem "Blydskap". Lexical cohesion is emphasized and this cohesive device is used as a strategy to indicate how meaningful patterns are created in the text. This analysis illustrates that the methods of text linguistics indeed provide useful tools for examining the construction of meaning in a text.

\section{Inleiding}

Die resultate van ondersoeke waarin aanvaar word dat kennis van die linguistiek 'n positiewe bydrae lewer tot 'n beter insig van 'n literêre teks is reeds jare lank wyd beskikbaar (vgl. plaaslik o.a. Hubbard, 1981; Du Plessis, 1983; Carstens, 1992, 1997; Robinson, 1999). Maar dit wil nie sê dat die metodes wat deur linguiste aangewend is in die beskrywing van die betrokke tekssoort se taligheid sonder meer aanvaar is nie. Noguchi (1991:365 e.v.) brei op hierdie saak uit deur daarop te wys dat die grootste probleem in hierdie verband geskep word deur die feit dat 'n literêre teks meer as een interpretasie regverdig. Die geldigheid of motiveerbaarheid van 'n linguis se verbandstelling tussen 'n bepaalde taalvorm en 'n spesifieke interpretasie word dan bevraagteken. Een van die strategieë wat Noguchi (1991:371) as 'n oplossing vir hierdie probleem voorstel, is om patrone op gelyksoortige linguistiese en betekenisvlakke in 'n teks te identifiseer: 
For instance, the isolation of verb types took place essentially on the syntactic level. If the analyst can find other syntactic patterns which link to the same (or similar) meaning as that suggested by the pattern of verb types, then these patterns add greater credence to the poisted form-meaning link.

Noguchi (1991:371) beskou die siening van 'n literêre werk as 'n "unified whole" as onderliggend aan hierdie strategie.

Die eenheidskarakter van 'n teks geld egter nie net vir 'n literêre teks as sodanig nie. Sonder om in groot besonderhede op die kwessie van 'n onderskeid tussen literêre en nie-literêre tekste in te gaan, is die mening van Hubbard (1981:112) hier van belang:

The fact that linguistics as a discipline can be of value in the study of literary texts is one that can only be properly appreciated if the view that there is such a thing as a 'literary language' which is completely different from a so-called 'ordinary language' is dispensed with (my kursivering - IAE).

Wybenga (1988:136) wys in dieselfde verband daarop dat verskynsels soos ikonisiteit, bevoorgronding en ander kenmerke van hegte tekste nie by uitstek die kenmerk van literêre tekste is nie. Alhoewel 'n kwantitatiewe verskil oor hierdie verskynsels daarin bestaan dat hulle dikwels meer in literêre as in ander tekssoorte voorkom, is dit volgens Wybenga (1988:136) steeds nie 'n objektiewe maatstaf om die verskil onder bespreking mee aan te dui nie:

Hiermee wil geensins beweer word dat daar geen verskil tussen literêre en ander tekste is nie, maar wil dit beklemtoon word dat hierdie verskil nie suiwer op die vlak van die taalgebruik gesoek kan word nie (my kursivering - IAE).

Die verskil lê volgens Wybenga (1988:136) eerder by die estetiese aspek. 'n Literêre werk spreek tot 'n leser op die vlak van die abstrakte die totaliteit daarvan is groter as die afsonderlike elemente en dit wat groter is, is die estetiese. Vergelyk ook Carstens (1997:85 e.v.) wat sê dat alhoewel 'n teks moeilik as literêr geklassifiseer kan word, daar tog op grond van vorm en funksie tussen verskillende teksgenres onderskei kan word, solank 'n betrokke teks die funksie van 'n literêre teks het. Sodanige teks sal in terme van die taalstruktuur ook alternatief funksioneer (Carstens, 1997:93). Cloete (1984:81) toon dat 'n literêre en 'n nie-literêre teks dieselfde elemente kan hê, aangesien hierdie elemente tot natuurlike taal behoort, maar in 'n literêre teks is hierdie elemente "kommunikatief komplementêr" en op so 'n wyse georganiseer dat die teks self uiteindelik as 'n konstruksie kommunikeer. En dit is hierdie 
kreatiewe kommunikasie waarna Wybenga (1988:136) verwys as die estetiese.

Om die talige elemente van byvoorbeeld 'n gedig vanuit 'n linguistiese oogpunt te ondersoek, behels nie om die voorgenoemde estetisiteit te bepaal nie, maar eerder om vas te stel hóé die taalelemente daarin aangewend word om 'n betrokke tema te skep. Van Peer (1991:7) wys in 'n oorsig oor die verband tussen linguistiese en literêre ondersoeke van teks op die volgende: "Traditional linguistics and literary methods should be combined (and not felt at odds) with more recent developments in text linguistics, pragmatics, discourse analysis and reception theory." Dit is dan volgens Carstens (1992:80) duidelik "dat die beginsels en metodes van die tekslinguistiek tóg 'n bydrae tot teksbegrip en teksinterpretasie kán lewer". Vergelyk in hierdie verband byvoorbeeld Robinson (1999) wat insgelyks poëtiese styl en die tekslinguistiek met mekaar in verband bring. Carstens (1992; 1997) wys uitgebreid op die winste van 'n (teks-)linguistiese benadering tot literêre tekste, terwyl Hubbard (1981:112) reeds tevore die volgende belangrike saak uitgelig het, naamlik die waarde van so 'n ondersoek in die bevordering van 'n meer effektiewe lees van 'n teks.

In hierdie artikel word vervolgens op grond van bostaande inleiding die volgende werkswyse gevolg:

- Eerstens word kortliks aan lesersoriëntering aandag gegee.

- Tweedens word die aard van lees as 'n betekeniskonstruksie van teks in oënskou geneem.

- Derdens sal uiteengesit word watter rol 'n teks se strukturele merkers tydens die interpretasieproses speel.

- Ten slotte word al die verworwe insigte kortliks toegepas op die gedig "Blydskap" uit die bundel Jukstaposisie (1982) van T.T. Cloete.

\section{Lesersoriëntering}

'n Leser neem 'n spesifieke oriëntering teenoor 'n teks in waarvolgens sy fokus tydens die leesproses gerig word. Dorfman (1996:456) wys op hierdie oriëntering se invloed:

Meanings do not lie dormant waiting to suggest themselves to readers; rather, it is the reader's perception of the text, or his or her 'interpretive model' that predisposes the reader to understand the text in a particular way. 
Rosenblatt (1994:1067) onderskei tussen 'n wetenskaplike en 'n estetiese lesersoriëntering (die een sluit die ander nie heeltemal uit nie), maar wys daarop dat alhoewel die ingenome oriëntering dikwels aan die leesdoel en 'n leser se keuse gekoppel kan word, dit nie die rol van die teks in die proses minimaliseer nie: elemente soos metafore, stilistiese konvensies en die afwyking van sekere linguistiese en semantiese konvensies word dikwels as medebepalend vir byvoorbeeld die literêre aard van 'n teks beskou (vgl. paragraaf 1 hierbo). Hierdie sake sal uiteraard vir 'n ervare leser as merkers of leidrade van 'n estetiese oriëntering teenoor 'n literêre teks dien, maar in sekere tekste wat as literêr getipeer word, kan hulle natuurlik ook ontbreek (vgl. ook Wybenga, 1988:57). Die persepsie van 'n teks as esteties word deur die lesersoriëntering beïnvloed en daarom sê Lamarque (1996:166) die volgende:

The very same text with the same textual meaning might be used for different purposes and thus might be subject to different interpretations: indeed, if the text is used now as a letter, now as a poem, it will be subject to different models of interpretation.

Hierdie saak sal uiteraard in die toepassingsfase van die artikel in gedagte gehou moet word.

\section{Lees as 'n konstruksie van teksbetekenis}

Lees moet beskou word as transaksioneel van aard - betekenis is in die vorige aanhaling aangedui as iets wat nie as 'n gegewe in 'n teks of in 'n leser voorkom nie, maar wat geskep word deur die onderliggende "transaksie" tussen leser en teks (vgl. Rosenblatt, 1994:1063). Begripsvorming tydens lees is dus 'n dinamiese konstruksieproses waarin leser en teks sentraal staan. Hierdie proses word veral gerig deur 'n leser se vermoë om die verskillende verhoudings wat tussen 'n teks se klanke, woorde, sinne en idees bestaan, te kan interpreteer.

\section{1 Teks en konteks}

'n Linguistiese ondersoek na die wyse waarop tekstuur in 'n teks geskep word, berus volgens Halliday en Hasan (1976:20) op twee soorte waarnemings:

The one concerns relations within the language, patterns of meaning realized by grammar and vocabulary; the other concerns the relations BETWEEN the language and the relevant features of the speaker's and hearer's (or writer's and reader's) material, social and ideological environment. Both these aspects of a text fall within the domain of linguistics. 
Die linguistiese patrone in 'n teks sluit 'n leser se ervaring van die werklikheid in, en verskaf tegelykertyd ook struktuur daaraan; dieselfde patrone maak dit óók moontlik "to identify what features of the environment are relevant to linguistic behavior and so form part of the context of situation" (Halliday \& Hasan, 1976:20).

'n Teks is dus koherent met betrekking tot twee aspekte: ten opsigte van die tekstuele konteks (dus eenvormig in register), en ten opsigte van die teks self (dus kohesief). 'n Leser reageer daarom op tweërlei wyse in sy transaksie met 'n teks: ekstern en intern

... [H]e uses not only linguistic clues but also situational ones. Linguistically he responds to specific features which bind the passage together, the patterns of connection, independent of structure, that we are referring to as cohesion. Situationally, he takes into account all he knows of the environment: what is going on, what part the language is playing, and who are involved (Halliday \& Hasan, 1976:20).

Teks en konteks is dus deurlopend in wisselwerking omdat 'n leser dié interaksie wil (en kan?) bewerkstellig (vgl. Wybenga, 1988:52). Hierdie twee sake, teks en konteks, waardeur kohesie en koherensie in teks tot stand kom, is dus onderskeibaar, maar nie skeibaar nie.

Om te ondersoek hoe taalelemente in 'n teks gebruik word vir die weergee van semantiese inhoud, moet 'n (teks-)linguistiese analise hiervan afgestem wees op die ontleding van die teks se samestellende dele; op hoe 'n skrywer intensioneel met die middele tot sy beskikking te werk gaan. Aangesien so 'n ondersoek uiteraard 'n groot omvang kan aanneem (vgl. Beukes, 1989), sal die toepassingsgedeelte van hierdie artikel hoogs selektief en illustratief uitgevoer moet word, maar met die gerigtheid van 'n (teks-)linguistiese ondersoek soos deur Halliday en Hasan (1976:328) verwoord: "The linguistic analysis of literature is not an interpretation of what the text means, it is an explanation of why and how it means what it does."

\subsection{Saamgestelde kommunikasie}

Hoe kommunikeer 'n literêre werk, of dan 'n gedig? Cloete (1984:16) wys op die poligrafiese aard van sodanige werk, en sê dat dit "uit 'n menigvuldigheid taal- en konseptuele elemente saamgestel is wat simultaan simboliseer en kommunikeer". Hierdie samestellende elemente betrek ook die tektoniek en perspektief van 'n werk. Die klem val vir die doeleindes van hierdie artikel op taalelemente en die bydrae wat hulle lewer tot die tekstualiteit van die gedig "Blydskap" (Cloete, 1982). Die besondere klem lê by die kohesie waarmee die bindingspatrone in 
die gedig blootgelê moet word, asook by koherensie as 'n beginsel van tekstualiteit - Carstens (1997:66) stel oor koherensie die volgende leidende vraag: "Is daar byvoorbeeld konseptuele skakeling tussen dit wat die taalgebruiker weet en dit wat hy uit die teks kan aflei?"

Die subsisteme in 'n teks behels onder andere die ordeningspatrone van idees, asook 'n lokale sowel as globale eenheidskepping, en 'n besondere aanwending van taalelemente. Die aangewese ondersoekbenadering om die komponente bloot te lê wat as subsisteme in 'n gedig werksaam is en tot die tekstuur daarvan bydra, is sisteem-analities van aard. Halliday (1985:xx) wys soos Cloete (1984:16) op die simboliese aard van die manier waarop betekenis in taal tot stand kom en sê: "It is not possible to point to each symbol as an isolate and ask what it means; the meaning is encoded in the wording as an integrated whole." Die strukturele eenhede van 'n teks moet volgens Van Dijk (1997:29) benader, beskryf en geïnterpreteer word "relative to preceding ones, as is most obvious in various forms of coherence. This discursive relativity may also involve functionality: later elements may have special functions with respect to previous ones. It also implies that language users operate, both mentally and interactionally, in an 'on-line' or 'ongoing' fashion, ...".

\section{Betekeniskonstruksie en merkers}

Tydens die mentale proses in die betekeniskonstruksie van 'n teks kies en organiseer 'n leser inhoude deur van sy bestaande kennis oor die organisasiestruktuur van 'n betrokke teksgenre gebruik te maak as 'n gids tot begripsvorming: om stukke teks in 'n verstaanbare geheel te omskep en globale koherensie daarvan te vorm. 'n Leser verbind 'n teks ook op 'n meer lokale vlak van die diskoersstruktuur: 'n teks voorsien leiding in hoe om die idees daarin te verbind (byvoorbeeld deur logiese verbinders en kohesiemiddele).

\subsection{Patroonvorming}

Een van die belangrikste aspekte in die betekeniskonstruksie van 'n teks is die interpretasie van die verskillende verhoudings wat tussen die woorde, sinne en idees daarvan bestaan, met ander woorde, 'n vraag na hoe 'n skrywer hierdie verhoudingsmoontlikhede op 'n unieke wyse ontgin. Sodanige interpretasie vereis kennis van die onderskeie merkers aan die hand waarvan hierdie verhoudings as patrone in 'n teks geskep word. Schiffrin (1980:231) beskryf die rol van merkers as deel van die metadiskoers wat dui op "the author's linguistic and rhetorical manifestation in the text in order to 'bracket the discourse organisation and the expressive implications of what is being said'”. Meyer (1984:119) 
verwoord die rol van teksmerkers soos volg: "Signaling has been defined as information in the text which gives emphasis to certain aspects of the semantic content or points out aspects of the structure of the content." Murdoch (1986:10) beskou die interpretasie van teksmerkers as 'n essensiële vaardigheid waarsonder 'n leser nie tot die betekeniskonstruksie van 'n teks kan kom nie. Merkers word ook beskryf as "contextualization cues" waarvan die betekenis implisiet is en wat binne 'n bepaalde konteks geïnterpreteer moet word: "Their signalling value depends on the participants' tacit awareness of their meaningfulness" (Gumperz, 1982:131). Hier word dus weer op die transaksionele aard van betekeniskonstruksie gewys.

Afgesien van die rol wat merkers speel, maak 'n leser terselfdertyd ook van afleiding as 'n leesstrategie gebruik om verhoudings tussen teksstruktuurelemente te skep. Goodman en Goodman (1994:115) beskryf die verband tussen die betekeniskonstruksieproses en die gebruikmaking van merkers en leesstrategieë soos volg: "As readers make use of all the language cues, they predict, make inferences, select significant features, confirm, and constantly work toward constructing a meaningful text."

Die voorgaande verwysing na merkers betrek die taalsisteem as geheel. Om 'n teks as betekenisvol te beleef, moet 'n leser dus binne die raamwerk van sy bestaande vaardigheid met organisatoriese en linguistiese tekselemente te werk gaan. Die leksiko-grammatiese sisteem behels die leksikon, die morfologie en die sintaksis van 'n taal, asook 'n aantal funksiewoorde, wat nie op sigself betekenisdraend is nie, maar tog bydra tot die vorming van patrone om 'n oneindige aantal betekenisse mee te kan uitdruk. 'n Ingeligte leser sal natuurlik in die geval van 'n gedig weet dat die versreël die wyse is waarop 'n digter talle elemente in die gedig tot patrone organiseer "wat as patrone kommunikatief is", en dat 'n versreël dikwels kontra-sintakties werk (Cloete, 1984:83) - 'n saak wat met die spesifieke teksgenre verband hou.

\subsection{Kohesie en koherensie}

Tekstuele betekenisimplikasie en ook eenheid ontstaan op 'n ontwikkelende manier in 'n gedig "deur 'n konstellasie betekenisse, deur interverbale betrokkenheid, deur die sinchroniese saamgaan van 'n reeks woorde, beelde, deur kruisverwysings en dergelike ... wat op verskeie plekke in die gedig staan en nie direk sintakties met mekaar verband hou nie" (Cloete, 1985:21). Om hierdie eenheid (teks-)linguisties na te vors en te toon hoe die eenheid in die betrokke gedig tot stand kom, moet die werking van kohesie en koherensie blootgelê word, aangesien kohesie 
"rekenskap gee van die essensiële semantiese verhoudings waarvolgens enige stuk taal (gesproke of geskrewe) kan funksioneer as teks ..." (Carstens, 2000:7).

Die konsep kohesie is deur Halliday en Hasan (1976) gevestig en word beskou as een van die maniere waarop die tekstuur van 'n teks geskep word. Kohesie is 'n semantiese konsep en volgens Halliday en Hasan (1976:11) verwys dit na

... relations of meaning that exist within the text, and define it as a text. Cohesion occurs where the INTERPRETATION of some element in the discourse is dependent on that of another. The one PRESUPPOSES the other, in the sense that it cannot be effectively decoded except by recourse to it.

Vergelyk Carstens (1997:110 e.v.) se uitgebreide uiteensetting van hierdie saak en veral sy verwysing dat kohesie geskep word deur die leksiko-grammatiese tekselemente se semantiese verwantskap met mekaar "terwyl koherensie hoofsaaklik betrekking het op die onderliggende konseptuele skakeling in 'n teks" (Carstens, 1997:116). Wybenga (1988:52) beklemtoon egter dat teks en konteks deurlopend in wisselwerking met mekaar is omdat 'n leser dié interaksie wíl bewerkstellig. Kohesie bewerkstellig dus semantiese verhoudings in 'n teks se leksiko-grammatika, terwyl koherensie die totale kohesiewe effek van die teks en die voorveronderstellinge van 'n skrywer en 'n leser omvat. Kohesie kan dus nie ondersoek word sonder om koherensie ook te betrek nie.

Vervolgens sal die manier waarop taalelemente in die gedig "Blydskap" (Cloete, 1982) ontgin en patrone geskep is, ondersoek word.1

\section{Blydskap}

$\begin{array}{ll}1 & \text { Dit is Maandag } \\ 2 & \text { vandag die sewende van } \\ 3 & \text { die welige somermaand November } \\ 4 & \text { dit is in die jaar negentientagtig } \\ 5 & \text { van die Here. Oorkant my werk 'n man } \\ 6 & \text { met 'n troffel en emmer. } \\ 7 & \text { met water en steen. Skielik begin } \\ 8 & \text { in my die dinge die een }\end{array}$

1 Vergelyk Hubbard (1981) en Carstens (1992; 1997) vir die winste van 'n (teks-) linguistiese benadering tot 'n ondersoek van hierdie aard. 
23

24

25

26

27

28

29

30 na die ander

hulle liefderik bedrywig besin

op mekaar. Die steen

voel op hom die koggelmander

loop. Vir die son

blits die troffel. Die wind stuit

fladderend teen die blaar.

Groot droom iets ontasbaars in 'n kokon

klein 'n konkrete mot. Die ruit

laat die wolk in hom vaar.

Ek hoor die messelende man

wat werkende sing

bly gevoelig nadenkend nie vergeet

nie dat in die plan

van God, dat in sy skepping

die baie bewus en blydskaplik weet

van die hardste steen en die dofste hout op die presiese plek en die presiese uur van elke vlerk en elke gewig word behoudende sout word suurdeeg wat deursuur en verlig.

(T.T. Cloete: uit Jukstaposisie)

\section{Toepassing}

Wybenga (1988:54) vra of binding (kohesie) die enigste funksie van kohesiemiddele in "Blydskap" (Cloete, 1982) is: verkry die kohesiemiddele dalk ook 'n samehangsbetekenis en het die boodskap van die gedig "iets met die samehang van alle dinge te doen ..."? Hierdie vrae sal in die loop van die toepassing in gedagte gehou word.

Aangesien die meer algemene betekenis in 'n teks deur grammatika en die meer spesifieke betekenis deur woordeskat uitgedruk word (Halliday \& Hasan, 1976:5) en kohesiewe verhoudings in dieselfde patroon uiteenval, word vervolgens hoofsaaklik gekonsentreer op laasgenoemde, naamlik die leksikale kohesiemiddele. In dié proses moet egter in gedagte gehou word dat 'n integrale beskrywing van ál die middele wat in 'n literêre werk kommunikatief bedrywig is, eintlik die ideaal is (Cloete, 1984:93), maar binne die beperkte omvang van hierdie artikel is dit noodsaaklik om die terrein af te baken. Voorts sal hier ook nie 'n bespreking van die verskillende kohesiemiddele gegee word nie - vergelyk Carstens (1997) vir 'n omvattende uiteensetting in hierdie verband. 
Die eerste soort leksikale kohesie wat ter sprake is, is kollokasie. Carstens (1997:331) wys op Stotsky (1983:438) se standpunt dat die kriteria om woorde as bydraend tot kollokasionele kohesie te bestempel, moeilik is om te identifiseer. ' $n$ Leser se vorige ervaring van sekere woorde wat neig om kontekstueel met mekaar geassosieer te word, help om hulle verwantskap met mekaar te herken. Volgens Carstens (1997:349) vorm woorde "slegs kollokasies omdat hulle voorkom in herhalende kombinasies in 'n teks" en hierdie herhaling is ook 'n kernfaktor in die skep van koherensie - die kollokasionele verhoudings wat deur herhaling geskep word, dra by tot beter oorhoofse begripsvorming van 'n teks.

\section{- Tydsverwysings}

Die volgende woorde in die betrokke gedig handel almal oor tyd:

"Maandag" (r. 1); "vandag" (r. 2); "die sewende" (r. 2); "die welige somermaand November" (r. 3); "die jaar negentientagtig" (r. 4); "die presiese uur" (r. 26). Op grond van tydsverwysing kan die voorgaande as semanties verwant beskou word - 'n verwantskap wat as lede van 'n ongeordende reeks beskryf kan word. Die blote herkenning van die verband tussen hierdie groep woorde lei nie noodwendig by 'n leser tot 'n bepaalde interpretasie nie.

Daar moet ook daarop gelet word dat die tyd as hier en nou beklemtoon word deur die gebruik van die teenwoordige tyd. Waarom die uitgebreide verwysing na tyd in strofe 1 ? Dit is 'n manier waarop die aardse tyd as "van die Here" beklemtoon word en by implikasie word die konkrete aardse bestaan met die bo-aardse verbind. Maar in hierdie bestaan is die spreker aan die tyd "van die Here" onderworpe. Sonder om die sintaksis in die besonder by die gesprek te betrek, moet daarop gelet word dat Cloete (1984:48 e.v.) die sintaksis beskou as betrokke by al die ander kommunikasievorme in 'n gedig. Die frase "van die Here" (r. 5) word voor in die vers geposisioneer en sodoende word die sin wat van r. 1 versgewys algaande verleng, voltrek as "van die Here." (r. 5) vergelyk ook "van God" (r. 23).

\section{- Assosiatiewe woordkeuses}

"Maandag/" (r. 1) is as 'n aanduiding van die aanvang van 'n werksweek kollokasioneel verwant aan "werk" (r. 5) en "werkende" (r. 20) wat in elk geval 'n sinonimiese verband toon. Buiten die voorgenoemde word die werkshandeling ontgin deur die assosiatiewe verhouding wat tussen sekere ander leksikale items geskep word. Die gedig spreek van werkshandelinge, van beweging en skepping, 'n kontinue proses van "word" in die hier en nou: "Oorkant my werk 'n man/" (r. 5); "Skielik begin/" (r. 7) "in 
my die dinge die een/" (r. 8) "na die ander/" (r. 9) "hulle liefderik bedrywig besin/" (r. 10) "op mekaar" (r. 11). Deur die opnoem van hierdie werkhandelinge word die digter se kreatiewe proses op grond van woordkeuse assosiatief aan die bouer se bouproses verbind.

Hoe word hierdie assosiasie in taal vergestalt? Afgesien van die anaforiese verband tussen "die dinge die een/" (r. 8) "na die ander/" (r. 9), "hulle" (r. 10) en "mekaar" (r. 11), vorm die volgende woorde 'n kollokasie en behoort 'n leser se voorkennis hom te laat let op die assosiasie tussen "liefderik bedrywig besin/" (r. 10), "sing/" (r. 20) en "gevoelig nadenkend" (r. 21) as woorde wat met 'n kreatiewe denkproses geassosieer kan word. Hiermee saam die opeenstapelende opnoem van "die dinge" (r. 8) wat hier soos 'n superordinaat funksioneer van alles wat vanaf reëls 11-18 die een na die ander volg sodat "besin/" (r. 10) "op mekaar." (r. 11) paradigmaties vergestalt word. In hierdie opeenstapeling word die aardse en die hemelse met mekaar in verband gebring om uiteindelik in r. 19 weer na die verteller, die werkende man en God terug te keer. Al die voorafgaande word nou saamgevat met "in die plan/" (r. 22) "van God" (r. 23) "dat in sy skepping/" (r. 23) sodat die laasgenoemde aan die voorafgaande werkproses verbind word.

\section{- Vooropstelling van temas deur herhaling}

Cloete (1984:34) wys op die tekstuele manier waarop woorde in 'n gedig beteken en "'n enkele woord staan [dus] in 'n organiese verhouding tot álle elemente (ook die nie-semantiese) van die hele teks". Alhoewel die fokus van hierdie artikel op leksikale items val, is die opvallende herhaling van 'n nie-semantiese woord soos "van" noemenswaardig: "(van) dag ... van" (r. 2); "van die Here." (r. 5); "van God" (r. 23); "van" (r. 25); "van" (r. 27). Die eerste en die laaste strofes roep mekaar deur hierdie herhaling op en die afhanklikheid van alle dinge word uitgehef, deur "van die Here" (r. 5); "van God" (r. 23) en daarna die aardse "van die hardste steen en die dofste hout/" (r. 25) en "van elke vlerk en elke gewig/" (r. 27), in die wordingsproses met mekaar te verbind. Deur herhaling word bepaalde temas in die gedig dus vooropgestel.

\section{- Intensivering en verbandlegging}

Voorts vind die wordingsproses na aanleiding van die inventaris van "die dinge" (r. 8) ook al hoe intenser plaas en is "bedrywig" (r. 10): "Die steen/" (r. 11) "voel op hom die koggelmander/" (r. 12) "loop", "Vir die son/" (r. 13) "blits die troffel" (r. 14), en dies meer. Let hier op die herhaling van "steen" en "troffel" in vergelyking met in r. 6 en r. 7, maar nou in 'n omgekeerde orde, om sodoende 'n assosiatiewe netwerk van die elemente te vorm. In die opnoem van al "die dinge" (r. 8) word antonimie (semanties verwante woorde) insgelyks ingespan om 'n 
verband te lê: "Groot droom iets ontasbaars in 'n kokon/" (r. 16) "klein 'n konkrete mot" (r. 17) - die kleine versoen met die ontasbare grootheid binne die bestek van wording, die jukstaponering om 'n harmoniese werking daar te stel. Ook "Die ruit/" (r. 17) "laat die wolk in hom vaar/" (r. 18) word 'n weer-spieëling van mekaar; ' $n$ toelaat van die proses van "liefderik bedrywig besin/" (r. 10) "op mekaar" (r. 11) - weer eens die assosiasie tussen die aardse en die hemelse.

In strofe 4 reflekteer die gedagte "Ek hoor die messelende man/" (r. 19) "wat werkende sing/" (r. 20) die vers in strofe 1, "Oorkant my werk 'n man/" (r. 5), maar nou meer intens - vergelyk ook "fladderend" (r. 15) en "bedrywig" (r. 10). Die twee verwysings in strofes 1 en 4 word tipografies omsluit deur die herhaling "van die Here" (r. 5) en "van God" (r. 23); terwyl ook "die dinge" (r. 8) en "die baie" (r. 24) sinonimies 'n eenheid tussen die gebeure van r. 8 tot $r$. 23 bewerkstellig. En hierdie proses van "besin" kulmineer in "bewus en blydskaplik weet/" (r. 24).

\title{
- Woordposisionering en leksikale herhaling
}

Volgens Cloete (1984:82) moet twee sake insake die literêre werk benadruk word:

\begin{abstract}
... eerstens dat dit 'n kommunikatiewe eenheid is van ' $n$ veelvoud van elemente, 'n homogeniteit van 'n heterogene aantal elemente: tweedens dat hierdie eenheid altyd ' $n$ bepaalde konstruksie is wat nie net 'n samevatting of versameling van die ander elemente is nie, maar sélf meespreek.
\end{abstract}

Dit is dan in hierdie verband wat woordposisionering sowel as leksikale herhaling gelees moet word. Die assosiasie tussen "die sewende van/" (r. 2); "die welige somermaand November/" (r. 2); "die jaar/" (r. 4); "van die Here" (r. 5); "liefderik bedrywig besin/" (r. 10); "werkende sing/" (r. 20); "gevoelig nadenkend/" (r. 21); "die plan/" (r. 22) "van God, dat in sy skepping/" (r. 23); "die baie bewus en blydskaplik weet/" (r. 24), word nie net kollokatief bewerkstellig nie, maar ook deur die herhaling van dieselfde woorde. Die assosiasie word ook fonies bewerkstellig sodat alles deel word van die volheid van die tyd, die genadetyd wat op 'n "presiese" manier kristalliseer in die slotstrofe waar die wordingsproses se Bybelse konnotasie, afgesien van die intertekstuele verwysings, pertinent uitgelig word met die herhaling van "van", "en", asook die bepaalde lidwoord "die" en die volgehoue proses met die woord "word". Veral foniese en morfologiese (-ste) herhaling speel in die proses ' $n$ rol. Halliday (1985) beklemtoon die verband tussen leksikale herhaling en verwysing (spesifiek die gebruik van "die") as 'n soort interaksie wat 'n belangrike beginsel vorm waarvolgens ' $n$ leser die patrone in 'n teks mee kan interpreteer. 


\section{- Bybelse konnotasies en die leser se voorkennis}

Om die Bybelse konnotasie van die slotstrofe as 'n hoogtepunt van die wordingsproses te beleef, moet 'n leser van voorkennis gebruik maak dus, al toon die teks so 'n ryk teenwoordigheid van kohesie tussen die onderskeie taalelemente, verg dit steeds 'n leser se inset om die teks in sy volle konsekwensie te verstaan. Die woorde "van die hardste steen" (r. 25) kan vir 'n ingeligte leser 'n assosiasie vorm met die Bybelse beskrywing van 'n sondige mens as iemand met 'n hart van klip; net so kan "word behoudende sout/" (r. 28) geassosieer word met gelowiges as die sout van die aarde. Die verwysing na "suurdeeg wat deursuur/" (r. 29) roep natuurlik ook 'n gelykenis van Christus en die gepaardgaande genadeboodskap op. Let ook op hoe die omarming as 'n patroon van woordgroepering in r. 28 en r. 29 (afgesien van die foniese herhaling) 'n toonbeeld van ikonisiteit lewer: "word behoudende sout/word suurdeeg wat deursuur/".

\section{- Alle tekselemente kommunikeer op 'n geïntegreerde wyse}

Cloete $(1984: 81)$ sê dat dit nie aanvaarbaar is "om ... te sê dat die literêre werk deur sy struktuur/konstruksie kommunikeer nie; die literêre konstruksie kommunikeer sélf, saam met al die ander tekselemente in die poligrafie van die literêre werk". Dit is hierdie aspek van totaliteit van al die geïntegreerde elemente wat in hulle kommunikatiewe funksie aan 'n gedig 'n "plus" voorsien. Cloete (1984:103) sê in hierdie verband ook dat volgorde as deel van die gebeure in 'n gedig kommunikatief is. Indien 'n woord in 'n gedig dus verplaas sou word, sal dit die boodskap versteur. Die blydskap waarna die titel van die gedig verwys, word dus deur 'n leser gesien en ervaar; sodoende kry die frase wat in die slotvers verwoord word ("en verlig" - r. 30) die betekenis van geestelike verligtheid. Die gedig kommunikeer inderdaad 'n samehang van alle dinge deur middel van velerlei talige en konseptuele elemente, maar dan ook in samewerking met 'n leser se inset.

\section{Samevatting}

In 'n poging om die winste van 'n (teks-)linguistiese ondersoek van die gedig "Blydskap" (Cloete, 1982) te toon, is kennis van die leksikale verhoudings in die analise van die gedig toegepas, sodat die betekenisverhoudings in die gedig, asook die verband daarvan met buitetekstuele betekenisse blootgelê kon word. Alhoewel dit geensins as volledig beskou kan word nie, kon die ondersoek na die digter se patroonmatige keuses wel op 'n verantwoordbare manier uitgevoer word (vgl. Carstens, 1997:65). As 'n sintese van die kern van hierdie poging word afgesluit met 'n aanhaling waarin die teoretiese sowel as praktiese aspekte wat in 
hierdie artikel aangeraak is, op 'n treffende manier weergegee word deur Weaver (1994:1199):

Just as the universe may be viewed as fundamentally a dance of transient forms that sparkle in and out of existence, so meaning, the poem, may be viewed as an ever-fluctuating dance that occurs more or less simultaneously on and across various levels: letters, words, sentences, schemata; text/reader and context; the present reader with other readers, past and present; and so forth; all connected in an multidimensional holarchy, an interlocking network or web of meaning, a synchronous dance in which there is no clear distinction between what is and what happens.

\section{Bibliografie}

Beukes, M.P. 1989. Vooropstelling, kohesie en koherensie in die poësie van T.T. Cloete. Potchefstroom : PU vir CHO. (M.A.-verhandeling.)

Carstens, W.A.M. 1992. Het die tekslinguistiek enige implikasies vir die studie van literatuur? Literator, 13(2):76-84, Aug.

Carstens, W.A.M. 1997. Afrikaanse tekslinguistiek. 'n Inleiding. Pretoria : Van Schaik.

Carstens, W.A.M. 2000. Tekslinguistiek en teksversorging. S.A. Tydskrif vir Taalkunde. Supplement, 37:4-17, Des.

Cloete, T.T. 1982. Jukstaposisie. Kaapstad : Tafelberg.

Cloete, T.T. 1984. Wat is literatuur? Potchefstroom : PU vir CHO. (Wetenskaplike bydraes van die $\mathrm{PU}$ vir $\mathrm{CHO}$ A.50.)

Cloete, T.T. 1985. Hoe om 'n gedig te ontleed. Pretoria : Academica.

Dorfman, M.H. 1996. Evaluating the interpretive community: evidence from expert and novice readers. Poetics, 23:450-470.

Du Plessis, H.G.W. 1983. Die verband tussen taal- en letterkunde. In: Sinclair, A.J.L. (red.) G.S. Nienaber - 'n Huldeblyk. Bellville : Universiteit van Wes-Kaapland Drukkers. p.

Goodman, Y.M. \& Goodman, K.S. 1994. To err is human: learning about language processes by analyzing miscues. In: Ruddell, R.B., Ruddell, M.R. \& Singer, H. (eds.) Theoretical models and processes of reading. Newark, Delaware : International Reading Association. p. 104-123.

Gumperz, J.J. 1982. Discourse strategies. Cambridge : Cambridge University Press.

Halliday, M.A.K. 1985. An introduction to functional grammar. London : Edward Arnold.

Halliday, M.A.K. \& Hasan, R. 1976. Cohesion in English. London : Longman.

Hubbard, E.H. 1981. The role of linguistics in the study of literary texts. In: MaxwellMahon, W.D. (ed.) Critical theory and literary texts. Pretoria : UNISA. p. 110125.

Lamarque, P. 1996. Marks and noises and interpretations. Semiotica, 108(1/2):163175.

Meyer, B.J.F. 1984. Organizational aspects of text: effects on reading comprehension and applications for the classroom. In: Flood, J. (ed.) Promoting reading comprehension. Newark, Delaware : International Reading Association. p. 113138.

Murdoch, G.S. 1986. A more integrated approach to the teaching of reading. English Teaching Forum, 24:9-15, Jan. 
Noguchi, R.R. 1991. Validating linguistic analyses of literary texts. Language and Style, 24(3):365-379, Summer.

Robinson, R. 1999. Metapoësie as digterlike leesstrategie. Tydskrif vir Literatuurwetenskap, 15(3/4):482-509, Des.

Rosenblatt, L.M. 1994. The transactional theory of reading and writing. In: Ruddell, R.B., Ruddell, M.R. \& Singer, H. (eds.) Theoretical models and processes of reading. Newark, Delaware : International Reading Association. p. 1057-1092.

Schiffrin, D. 1980. Metatalk: organisational and evaluative brackets in discourse. Sociological Inquiry, 50:199-236.

Stotsky, S. 1983. Types of lexical cohesion in expository writing: implications for developing the vocabulary of academic discourse. College Composition and Communication, 34:430-446.

Van Dijk, T.A. 1997. The study of discourse. In: Van Dijk, T.A. (ed.) Discourse as structure and process. Discourse studies: a multidisciplinary introduction. Vol. 1. London : SAGE. p. 1-34.

Van Peer, W. (ed.) 1991. The taming of the text-explorations in language, literature and culture. London/New York : Routledge.

Weaver, C. 1994. Parallels between new paradigms in science and in reading and literary theories: an essay review. In: Ruddell, R.B., Ruddell, M.R. \& Singer, H. (eds.) Theoretical models and processes of reading. Newark, Delaware : International Reading Association. p. 1185-1202.

Wybenga, D.M. 1988. Diskoersanalise en stilistiek. Pretoria : Serva.

\section{Kernbegrippe:}

leksikale kohesie/merkers

lesersoriëntering

literêre teks

tekslinguistiek

\section{Key concepts:}

lexical cohesion/cues

literary text

reader's orientation

text linguistics 
